\title{
Field validation of imaging an adjacent borehole using scattered P-waves
}

\author{
Jian-Lin Ben ${ }^{1,2} \cdot$ Wen-Xiao Qiao ${ }^{1,2} \cdot$ Xiao-Hua Che ${ }^{1,2} \cdot$ Xiao-Dong Ju$^{1,2} \cdot$ Jun-Qiang Lu ${ }^{1,2} \cdot$ Bai-Yong Men ${ }^{1,2}$
}

Received: 30 November 2019 / Published online: 2 July 2020

(c) The Author(s) 2020

\begin{abstract}
Acoustic waves enter a rock formation from a borehole and are reflected or scattered upon encountering a geologic structure. Consequently, we obtain the structure location represented by the azimuth and distance from the borehole using the acoustic reflection or scattering. Downhole acoustic measurements with the azimuthal resolution are realized using an azimuthal acoustic receiver sonde composed of several arcuate phased array receivers. Eight sensors distributed evenly across the arcuate phased array receiver can record acoustic waves independently; this allows us to adopt the beamforming method. We use a supporting logging tool to conduct the downhole test in two adjacent fluid-filled boreholes, for validating the evaluation of the geologic structure using scattered P-waves. The test results show the multi-azimuth images of the target borehole and the azimuthal variation in scattering amplitudes. Thus, we obtain the precise location of the target borehole. Furthermore, the measured values of the target borehole are consistent with the actual values, indicating that we can accurately evaluate a near-borehole geologic structure with scattered P-waves.
\end{abstract}

Keywords Acoustic logging $\cdot$ Acoustic imaging $\cdot$ Scattering exploration $\cdot$ Beamforming

\section{Introduction}

Geologic structures are usually associated with the generation, migration, and accumulation of hydrocarbons in a rock formation. Seismic scattered waves due to small-scale heterogeneous structures are acquired by seismic geophones, which can be used to evaluate geologic structures. Considerable research has been conducted pertaining to the theories of seismic scattering (Aki 1969; Aki and Chouet 1975; Wu 1982; Wu and Aki 1985) and reservoir exploration using scattered waves (Yilmaz 2001; Maercklin et al. 2004; Willis et al. 2006; Fang et al. 2014). An essential factor of seismic migration imaging is the determination of velocities of the elastic waves accurately; however, the conventional

Edited by Jie Hao

Xiao-Hua Che

aclab@cup.edu.cn

1 State Key Laboratory of Petroleum Resources and Prospecting, China University of Petroleum (Beijing), Beijing 102249, China

2 Key Laboratory of Earth Prospecting and Information Technology, Beijing 102249, China velocity analysis method is not suitable for a heterogeneous rock formation involved in scattering seismic exploration (Gou 2007). Besides, low-frequency seismic waves result in low-resolution seismic images of small-scale structures. Acoustic well logging can continuously record the elastic properties of the rock formation surrounding a borehole, enabling accurate measurements of $\mathrm{P}$ - and S-wave velocities. Over the last two decades, acoustic reflection-imaging logging has maintained high-accuracy measurements of wave slowness and has extended the detection distance from one meter to tens of meters, which has become a feasible and effective evaluation method for small-scale structures in the vicinity of the borehole (Yamamoto et al. 2000; Chabot et al. 2001; Tang 2004; Tang and Patterson 2009).

Previous studies on reservoir exploration using scattered waves mainly focused on long-wavelength seismic waves. However, studies on the downhole acoustic field are lacking. In the downhole acoustic measurements, most of the energy is concentrated in a rock formation near the borehole wall, and the acoustic attenuation of the rocks saturated by fluids cannot be ignored. Therefore, it is challenging to identify the scattered waves from the acoustic data. Zhang et al. (2009) applied the equivalent offset migration (EOM) method in acoustic reflection-imaging logging and obtained improved 
geologic structure images from low signal-to-noise ratio (SNR) acoustic data. Su et al. (2014) numerically simulated the wave field in dipole S-wave logging, in the presence of a formation interface and a liquid-filled openhole, and concluded that the reflection amplitude values of the former are three times that of the latter. Tang et al. (2016a) conducted numerical calculation of acoustic scattering in a borehole environment, and his conclusions indicated that the main component of the coda waves in a horizontally heterogeneous rock formation is scattered waves. Tang et al. (2016b) also used cross-dipole sources to detect a liquid-filled borehole located in a remote formation and analyzed the acoustic scattering. Although the scale of a target borehole is smaller than the S-wave wavelength in the formation, the scattered $\mathrm{SH}$-wave can also be received by the logging tool. In recent years, the developed azimuthal acoustic well logging can receive the azimuthal $\mathrm{P}$-waves from different directions along the borehole circumference, which helps us obtain the azimuthal variation in an acoustic field by beamforming method (Haldorsen et al. 2006, 2010; Maia et al. 2006; Qiao et al. 2011; Wu et al. 2012; Che et al. 2014a, b, 2016, 2017; Yang et al. 2019a, b). The beamforming method can help us effectively enhance the acoustic reflections in a borehole environment (Yang et al. 2019c). As far as we know, most of the studies concentrated on the beamformed results obtained by stacking of all eight sensors' data, such as an adaptive block-frost beamformer (Haldorsen et al. 2006) or a high-resolution adaptive beamformer ( $\mathrm{Li}$ and Yue 2015). However, the reflections are always effectively received by the three sensors facing the reflector, also called effective sensors, while the oppositely placed sensors are not as receptive, due to the back lining inside the receiver ring. Therefore, the in-phase stacking results can be perfectly realized by effective sensors instead of eight sensors.

In this study, we propose an azimuthal acoustic measuring method in a borehole environment that can record the azimuthal acoustic data. Then, we experimentally verify the performance of the proposed method in two adjacent boreholes. In the validation with field results, we directionally enhance the scattered P-waves by utilizing the beamforming method and obtaining a precise location and clear scattering image of the target borehole.

\section{Methodology}

\subsection{Azimuthal acoustic measurements in a borehole environment}

An acoustic well-logging tool consists of an azimuthal acoustic receiver sonde $R$ and a transmitter sonde $T$, as shown in Fig. 1. Several monopole sources serve as the transmitter sonde. The tool is centered in a vertical

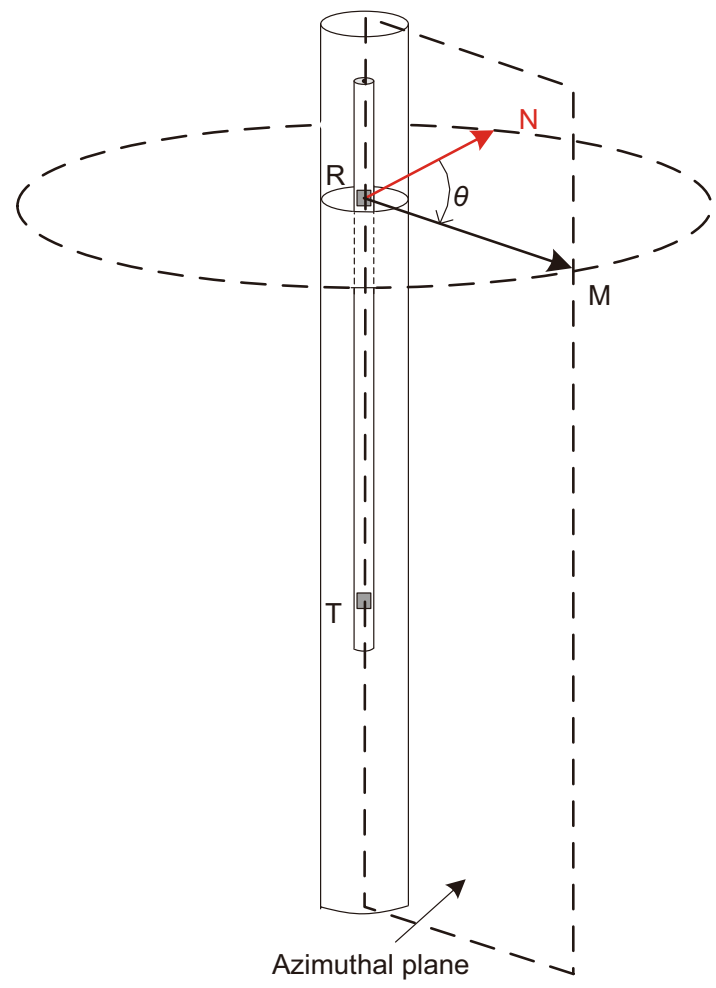

Fig. 1 Schematic of the azimuthal acoustic measurements in a borehole environment. $\theta$ is the azimuth of the acoustic waves

borehole, and the connecting line between the transmitter $T$ and receiver $R$ is the axial line of the borehole. We draw a horizontal vector RM from the receiver $R$ in the cross-section of the borehole; thus, the azimuthal plane is a half-plane composed of $\mathbf{R M}$ and the axial line. Consequently, the azimuthal reference angle of the azimuthal plane, abbreviated as azimuth and denoted as $\mathrm{N} \theta$, is an angle formed by the clockwise rotation of the north-facing vector $\mathbf{R N}$ to $\mathbf{R M}$ in the range of $0^{\circ}-359^{\circ}$. However, an assumption is made here that the acoustic waves from a geologic structure in any azimuthal plane can be obtained; thus, the azimuth of the geologic structure is revealed by the maximum value of the wave amplitudes. For example, a geologic structure with an azimuth of $\mathrm{N} 180^{\circ}$ means that it is located south of the borehole.

The azimuthal acoustic receiver sonde, as shown in Fig. 2, includes ten arcuate phased array receivers, numbered $R_{1}-R_{10}$. Adjacent receivers are $0.20 \mathrm{~m}$ apart, and the distance from the center of the transmitter sonde to the first receiver $R_{1}$, also known as the minimum offset, is $5.55 \mathrm{~m}$. The receiver is composed of eight piezoelectric vibrators uniformly distributed along the circumference of the tool, and each sensor can be regarded as an array element of the phased array, numbered $E_{1}-E_{8}$. 


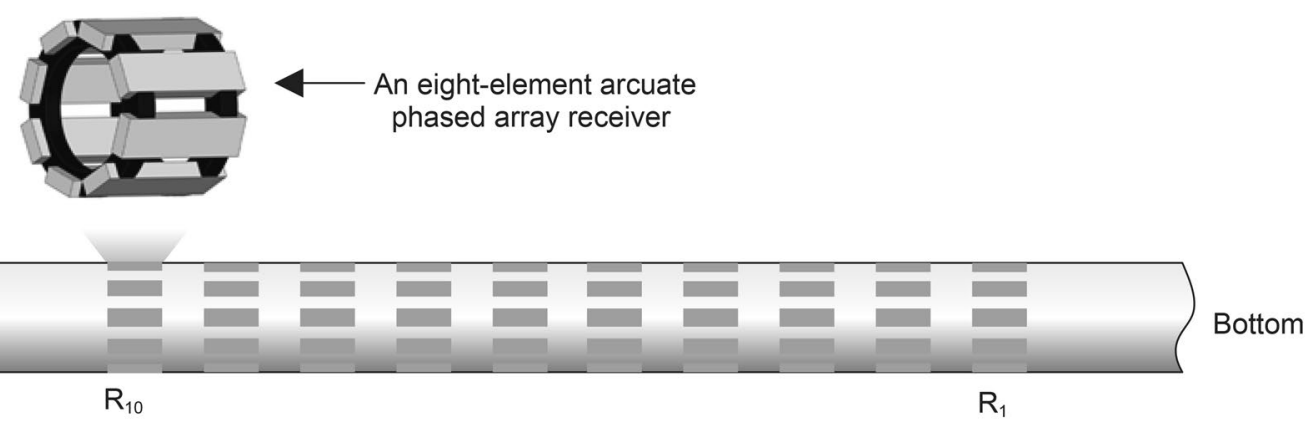

Fig. 2 Schematic of an azimuthal acoustic receiver sonde

\subsection{Beamforming method for azimuthal acoustic data}

A geologic structure is situated far from the borehole; therefore, the reflected or scattered waves can be regarded as a series of plane waves. As shown in Fig. 3a, eight sensors of an arcuate phased array are evenly spaced, with the sensor $E_{1}$ facing northward, then the azimuth $\theta$ of the incident waves is an angle formed from the clockwise rotation of the northto-incident direction. For simplicity, three adjacent sensors form a phased subarray. The incident waves propagating from east to west are received by sensor $E_{3}$ first; thereafter, the delay times of the wave arrivals at sensors $E_{2}$ and $E_{4}$ are represented by as $\tau_{1}(\theta)$ and $\tau_{2}(\theta)$, respectively. In order to obtain the delay times, the coordinate is established with the center of the circumference sensor distributed as an origin, the $x$-axis is opposite to the incident direction and the radius is $4 \mathrm{~cm}$, as shown in Fig. 3b. Then, $\tau_{1}(\theta)$ and $\tau_{2}(\theta)$ are related to the three largest $x$ values of the sensors' coordinates. The azimuth of the sensor $E_{i}(i=1,2,3, \ldots, 8)$ is expressed as
$\theta_{E_{i}}=45(i-1)$; thus, the coordinates of sensors $E_{2}, E_{3}$, and $E_{4}$ are expressed as $\left(\operatorname{rad} \cos \left(\theta-\theta_{E_{2}}\right), \operatorname{rad} \sin \left(\theta-\theta_{E_{2}}\right)\right)$, $\left(\operatorname{rad} \cos \left(\theta_{E_{3}}-\theta\right),-\operatorname{rad} \sin \left(\theta_{E_{3}}-\theta\right)\right)$, a $\mathrm{n}$ d $\left(\operatorname{rad} \cos \left(\theta_{E_{4}}-\theta\right),-\operatorname{rad} \sin \left(\theta_{E_{4}}-\theta\right)\right)$, respectively. Accordingly, $\tau_{1}(\theta)$ and $\tau_{2}(\theta)$ can be expressed as follows:

$$
\begin{aligned}
& \tau_{1}(\theta)=\operatorname{rad}\left(\cos \left(\theta_{E_{3}}-\theta\right)-\cos \left(\theta-\theta_{E_{2}}\right)\right) / v \\
& \tau_{2}(\theta)=\operatorname{rad}\left(\cos \left(\theta_{E_{3}}-\theta\right)-\cos \left(\theta_{E_{4}}-\theta\right)\right) / v
\end{aligned}
$$

where $v$ is the velocity of the incident waves.

Hence, the beamformed wave is obtained by adding the waveforms of sensors $E_{2}$ and $E_{4}$, shifted by $\tau_{1}(\theta)$ and $\tau_{2}(\theta)$, to sensor $E_{3}$, respectively. The waveform of sensor $E_{i}$ is expressed as $W F_{E_{i}}(t)$; therefore, the beamformed waveform $W F(\theta, t)$ with an azimuth of $\theta$ can be expressed as:

$$
W F(\theta, t)=W F_{E_{2}}\left(t+\tau_{1}(\theta)\right)+W F_{E_{3}}(t)+W F_{E_{4}}\left(t+\tau_{2}(\theta)\right)
$$

Generally, the incoming reflections will not propagate in the horizontal plane; thus, the delay times of sensors are not (a)

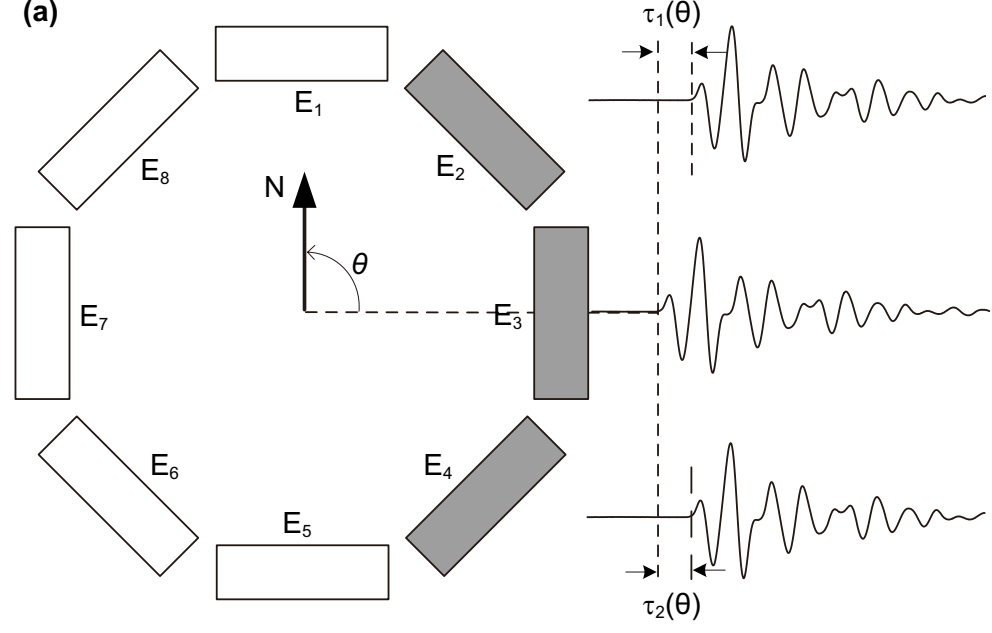

(b)

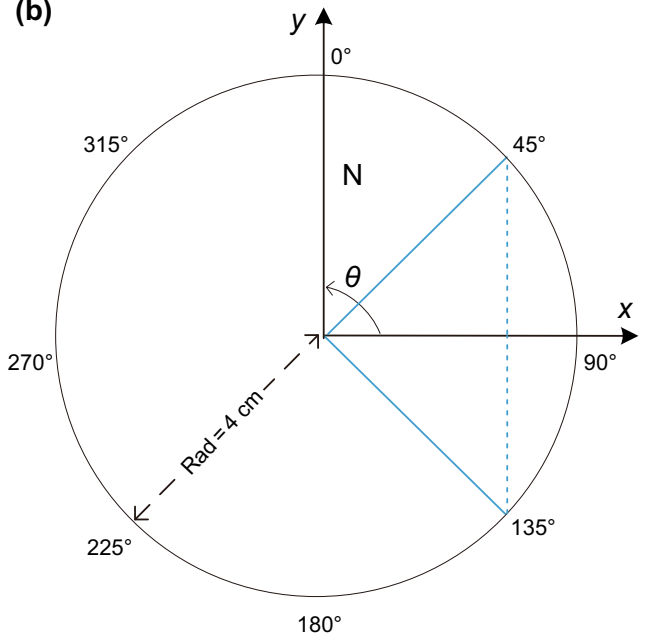

Fig. 3 Schematic of the beamforming method based on the three-element subarray. $\mathbf{a} \theta$ is the azimuth of the incident waves and $\mathbf{b} \tau_{1}(\theta)$ and $\tau_{2}(\theta)$ are related to the three largest $x$ values of the coordinates of sensors in subarray 
only related to the azimuth $\theta$ but also the vertical angle $\varphi$, which is the angle between wave direction and horizontal plane. Where $\varphi>0$, the downgoing waves; $\varphi<0$, the upgoing waves; and $\varphi=0$, the waves propagate in the horizontal plane. Therefore, the $\tau_{1}(\theta)$ and $\tau_{2}(\theta)$ can be expressed as follows:

$\tau_{1}(\theta)=\operatorname{rad} \cos \varphi\left(\cos \left(\theta_{E_{3}}-\theta\right)-\cos \left(\theta-\theta_{E_{2}}\right)\right) / v$

$\tau_{2}(\theta)=\operatorname{rad} \cos \varphi\left(\cos \left(\theta_{E_{3}}-\theta\right)-\cos \left(\theta_{E_{4}}-\theta\right)\right) / v$

For the plane waves propagate from south to north, we select a subarray composed of sensors $E_{4}, E_{5}$, and $E_{6}$, and a new coordinate to obtain the beamformed waveform with an azimuth of $\mathrm{N} 180^{\circ}$ by the same method. There are eight three-element subarrays in an arcuate phased array, but each of them can output several beamformed waveform traces with different azimuths. Thus, the waveform with the given azimuth is obtained using the corresponding subarray and delay times. Once the azimuth of the beamformed waveform is close to the propagation direction of the azimuthal acoustic waves, the stack is in-phase. As a consequence, the maximum amplitude value among these beamformed waveforms corresponds to the azimuth of the geologic structure.

\section{Azimuthal acoustic data processing workflow}

The schematic of the azimuthal acoustic data processing workflow is shown in Fig. 4. The logging tool is equipped with monopole sources and azimuthal sensors, and the waves are labeled as $M R_{i} E_{j}$, where $i$ is the receiver number and $j$ is the sensor number. Typical frequency-wavenumber $(f-k)$ transform (Hornby 1989) is used to data denoising and wave separation. The slowness-time correlation (STC) method is used to obtain the P-wave slowness. For determining the azimuth of the geologic structure, the azimuthal variation in reflection or scattering amplitudes from beamformed waveforms is obtained. In addition, multi-azimuth images are obtained using separated reflected or scattered waves. Consequently, the results of the azimuthal acoustic data inversion reveal the geological parameters of structures, such as azimuth, strike, dip, and dipping azimuth.

\section{Field test in two adjacent boreholes}

For verifying the performance of the azimuthal acoustic measurements in a borehole environment, a field test in two adjacent boreholes, separated by $10.0 \mathrm{~m}$, was performed in Qiandao Lake, eastern China. The maximum depth of both the boreholes was approximately $200 \mathrm{~m}$, of which the upper parts were cased holes. As shown in Fig. 5, the diameter

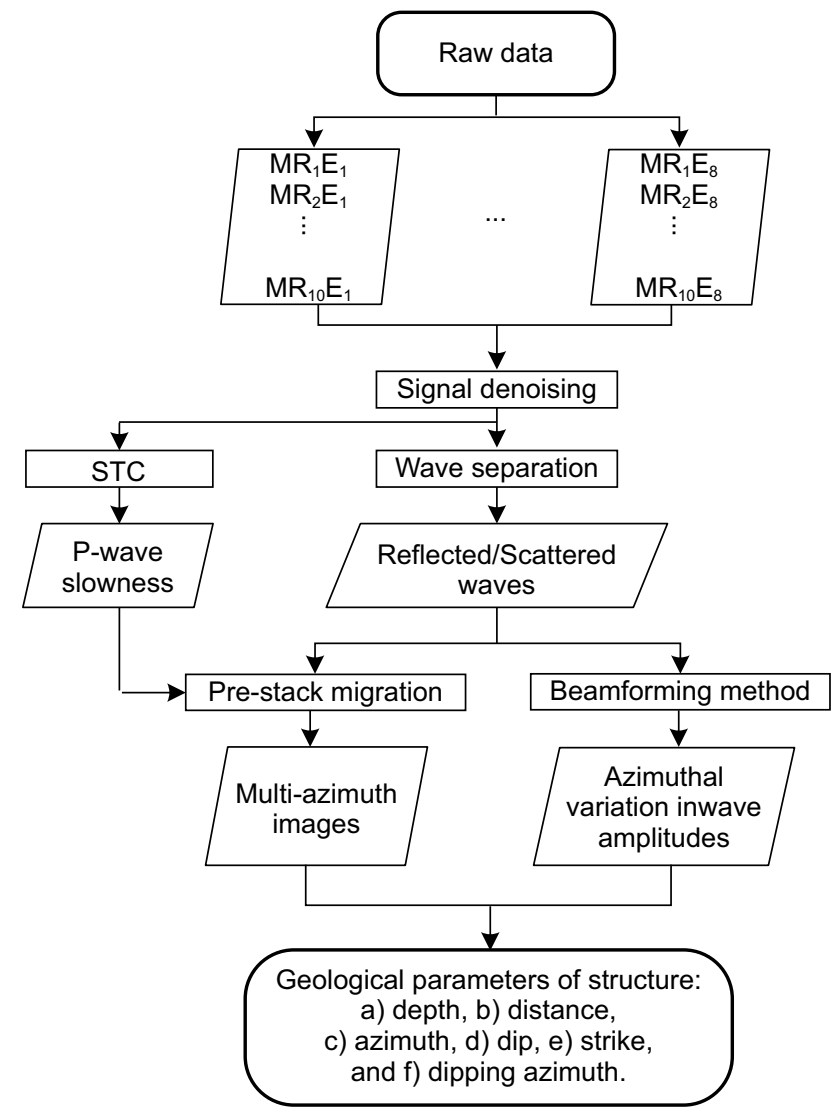

Fig. 4 Processing workflow of the azimuthal acoustic data

of the borehole in which the tool is located is $21.6 \mathrm{~cm}$ ( $8.50 \mathrm{in}$.), and the diameter of the target borehole is $24.1 \mathrm{~cm}$ (9.50 in.). The target borehole is located on the south side of the tool, with the angle from the connecting line of the two boreholes to the north being approximately $33^{\circ}$ and its azimuth at $\mathrm{N} 147^{\circ}$.

\section{Validation of field results}

\subsection{Scattered P-waves from the target borehole}

Figure 6 shows the waves of the eight sensors in receiver $R_{1}$. The solid line in the left panel is the gamma curve (GR), and the dotted line is the tool azimuth curve (AZ), which represents the azimuth of the sensor $E_{1}$. The waves of the sensors are plotted in the eight panels. From Fig. 6, the value variation of the $\mathrm{AZ}$ curve is not apparent, indicating that the tool hardly rotates while in operation. Above the depth of $40 \mathrm{~m}$, casing waves with constant arrival times and strong amplitudes are observed. Borehole mode waves such as P-, $\mathrm{S}-$, and ST waves are observed for the openhole. When the borehole wall is ruptured, the mode waves become weak at multiple measurement depths, except for the ST waves. 

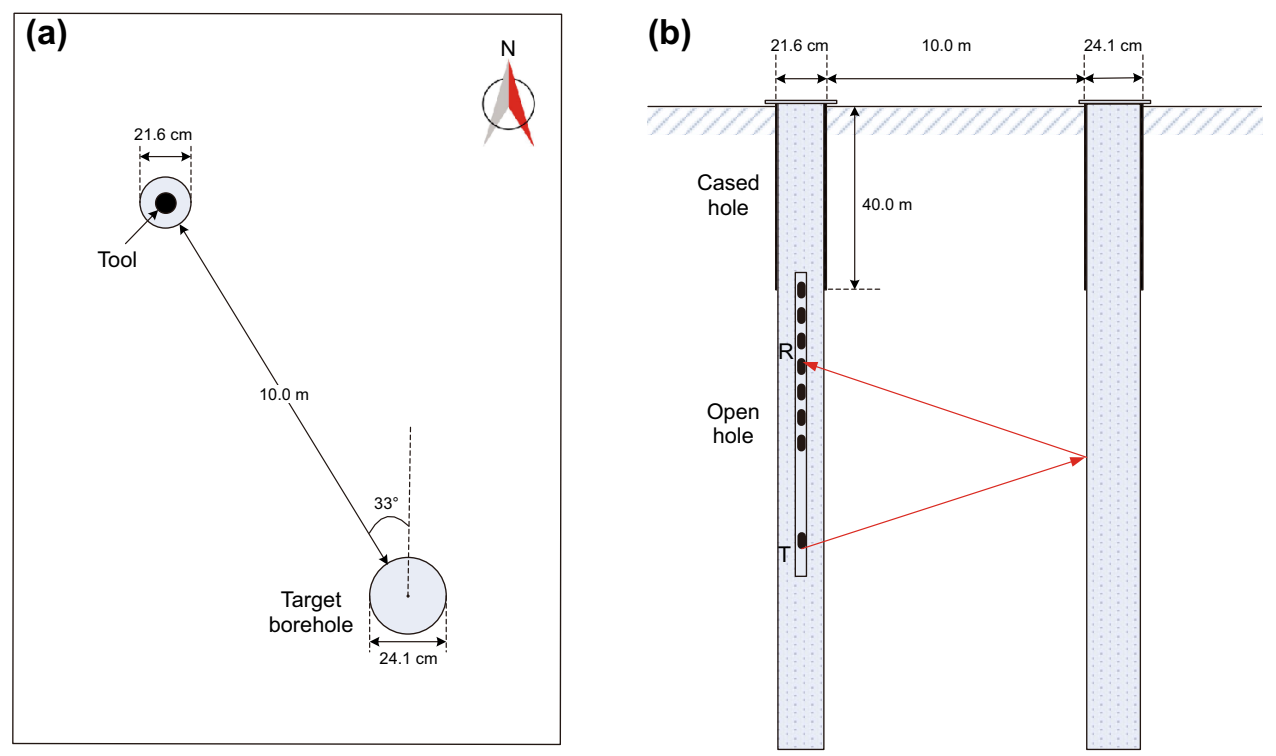

Fig. 5 Schematic of a field test in two adjacent boreholes of diameters $21.6 \mathrm{~cm}$ (borehole with the tool) and $24.1 \mathrm{~cm}$ (target borehole). a Top view and $\mathbf{b}$ side view. The target borehole is $10.0 \mathrm{~m}$ away from the tool, with an azimuth of $\mathrm{N} 147^{\circ}$

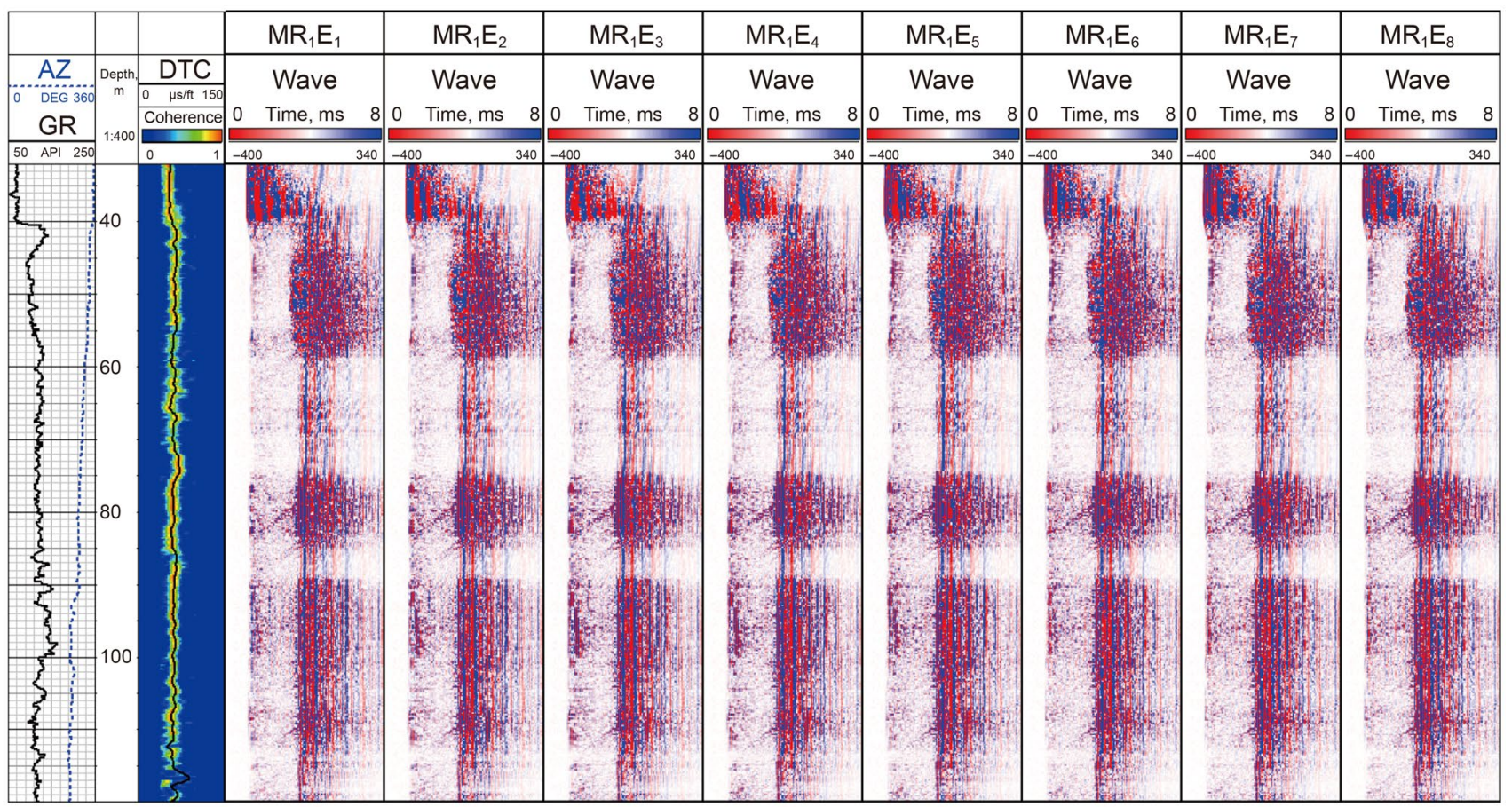

Fig. 6 Waves of the eight sensors in receiver $\mathrm{R}_{1}$ and the P-wave slowness curve

Owing to the borehole mode waves, we cannot directly observe the acoustic waves from the target borehole; therefore, it is necessary to filter the mode waves using a frequency-wavenumber $(f-k)$ transform (Hornby 1989). The separated waveform is shown in Fig. 7. Based on the P-wave slowness (about $5000 \mathrm{~m} / \mathrm{s}$ ) and distance $(10.0 \mathrm{~m}$ ) between the two boreholes, the P-wave from the target borehole received by the sensor $E_{7}$ in receiver $R_{1}$, at a depth of $98.8 \mathrm{~m}$, is marked by the dashed frame and its amplitude spectrum (dashed line) is also obtained. In Fig. 7, the domain frequency of the $\mathrm{P}$-wave is approximately $10.3 \mathrm{kHz}$; therefore, the P-wave wavelength in the rock formation is 


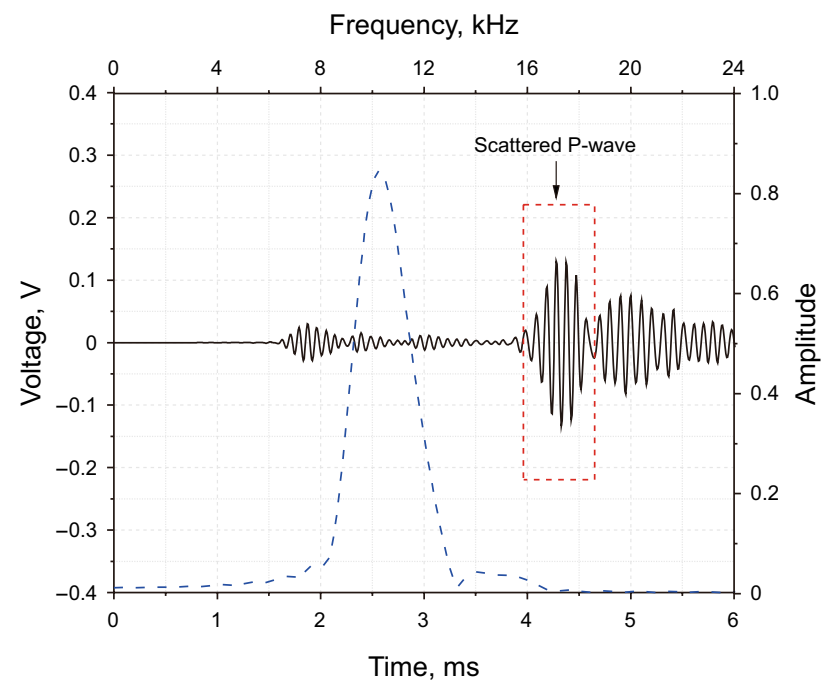

Fig. 7 Waveform and amplitude spectrum (dashed line) of scattered P-wave from the target borehole

approximately $50.0 \mathrm{~cm}$, which is twice the diameter of the target borehole. Thus, the $\mathrm{P}$-waves from the target borehole are scattered $\mathrm{P}$-waves instead of reflected P-waves.

The separated scattered P-waves of eight sensors are shown in Fig. 8. The scattered P-waves are marked by the red dashed line, among which $M R_{1} E_{6}$ and $M R_{1} E_{7}$ are apparent. As the $\mathrm{AZ}$ value is approximately $\mathrm{N} 260^{\circ}$, the azimuths of the eight sensors are $\mathrm{N} 260^{\circ}, \mathrm{N} 305^{\circ}, \mathrm{N} 350^{\circ}, \mathrm{N} 35^{\circ}, \mathrm{N} 80^{\circ}$, $\mathrm{N} 125^{\circ}, \mathrm{N} 170^{\circ}$, and $\mathrm{N} 215^{\circ}$. Therefore, we can infer that the sensors $E_{6}$ and $E_{7}$ face the target borehole, and the correspondence between the azimuthal variation of scattering (Fig. 8) and the location distribution of the two boreholes (Fig. 5) is clear.

\subsection{Azimuth of the target borehole}

According to the azimuths of the sensors and the amplitude values of the scattered P-waves in Fig. 8, the approximate azimuth of the target borehole is obtained. However, the measurement error cannot be ignored due to the similarity between the scattering amplitudes of the adjacent sensors. Therefore, we use the beamforming method to directionally receive the scattered P-waves and improve the accuracy of the measurements. Figure 9a shows the eight waveform traces of receiver $R_{1}$, where the dotted ellipse indicates the scattered P-waves. Thirty-seven beamformed waveform traces with $10^{\circ}$ azimuth interval are plotted in Fig. $9 \mathrm{~b}$.

The relationships between the normalized amplitude values of the scattered P-waves in Fig. 9 and the azimuths are shown in Fig. 10, in which the red and black lines indicate the amplitude values of scattered P-waves with and without beamforming, respectively. The amplitude values of the black line with the azimuths of $\mathrm{N} 125^{\circ}$ and $\mathrm{N} 170^{\circ}$ are similar to each other; therefore, it is easy to obtain the inaccurate azimuth of the target borehole. However, the maximum amplitude values of the red line, with an azimuth of $\mathrm{N} 150^{\circ}$, clearly indicates the azimuth of the target well, which is close to its actual value $\mathrm{N} 147^{\circ}$.

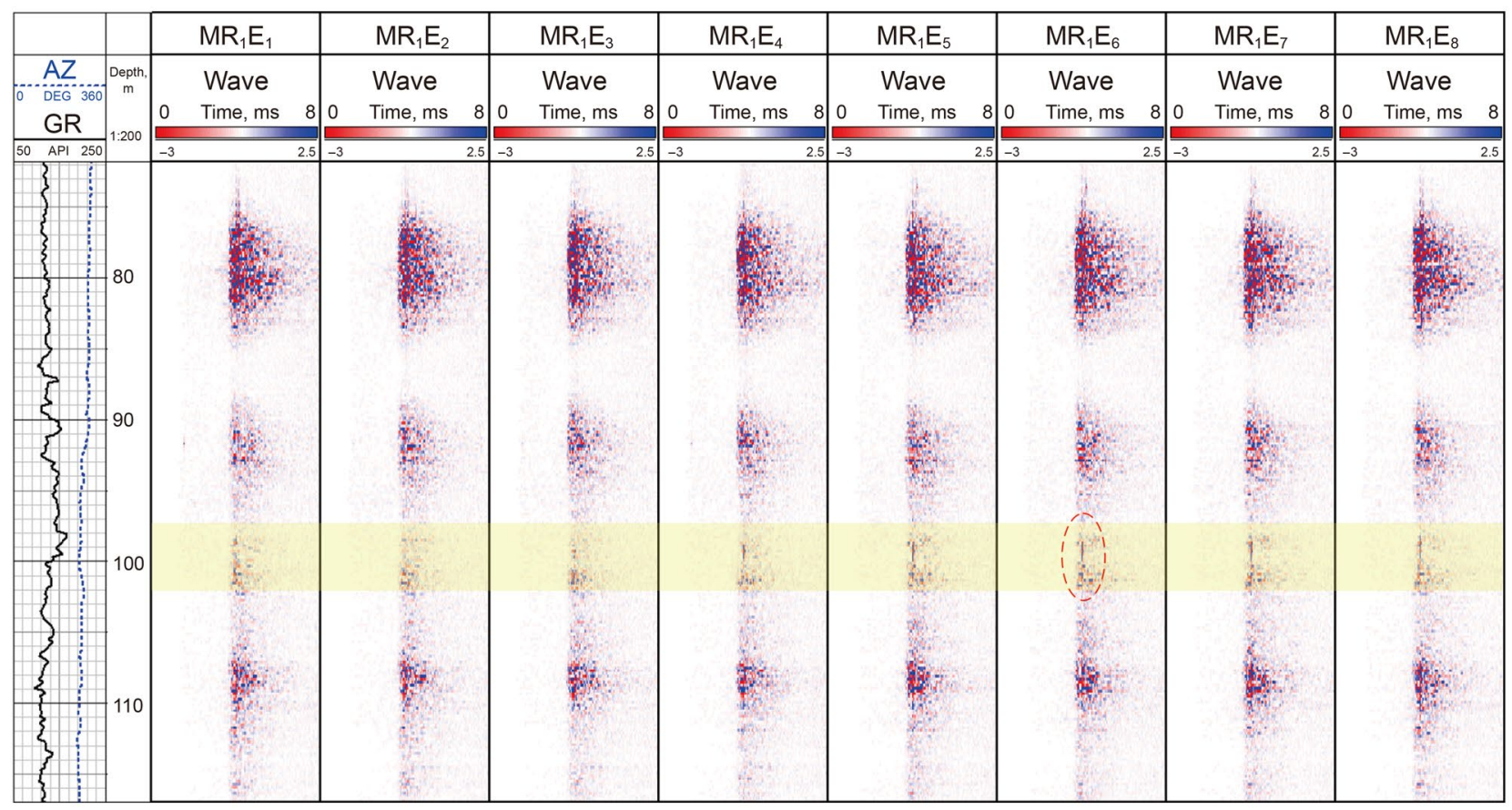

Fig. 8 Scattered P-waves of eight sensors with azimuths of $\mathrm{N} 260^{\circ}, \mathrm{N} 305^{\circ}, \mathrm{N} 350^{\circ}, \mathrm{N} 35^{\circ}, \mathrm{N} 80^{\circ}, \mathrm{N} 125^{\circ}, \mathrm{N} 170^{\circ}$, and $\mathrm{N} 215^{\circ}$ 

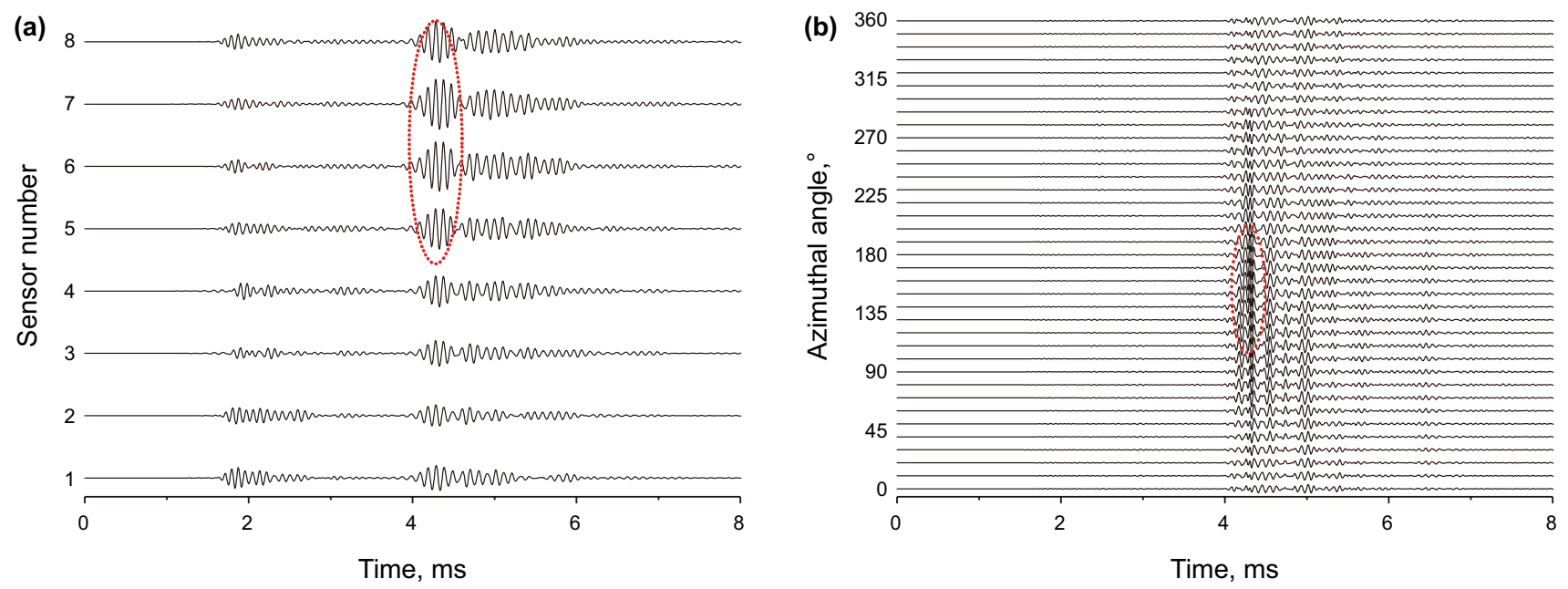

Fig. 9 Waveforms of a scattered P-waves and $\mathbf{b}$ beamformed scattered P-waves

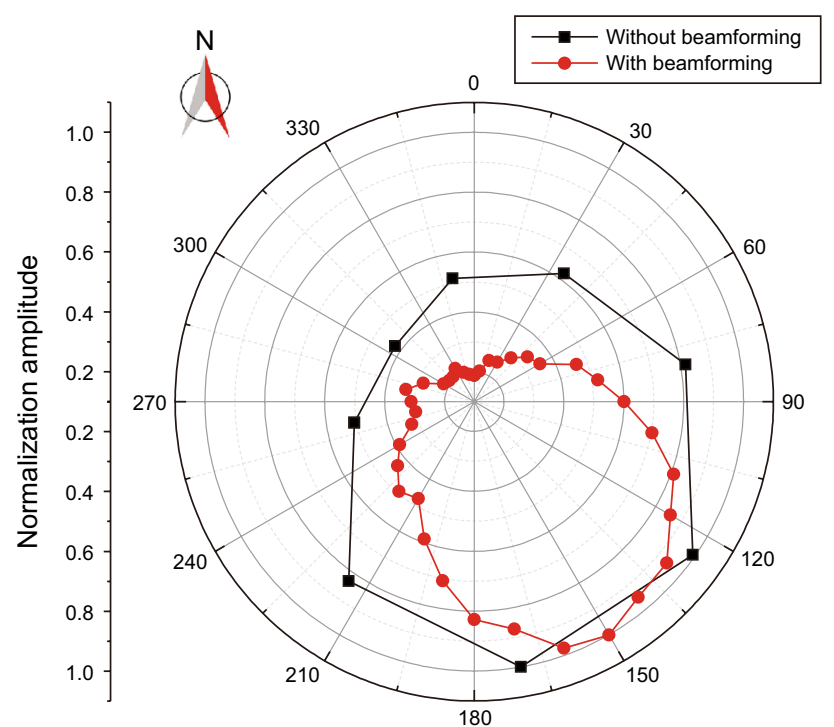

Fig. 10 Azimuthal variation in the amplitude values of the scattered P-waves with (red line) and without (black line) beamforming. The maximum amplitude value corresponds to the azimuth of the target borehole. The former azimuth is $\mathrm{N} 150^{\circ}$, while the latter is $\mathrm{N} 170^{\circ}$. The measurement accuracy of the former is better

\subsection{Multi-azimuth images of the target borehole}

The beamforming method is applied to obtain the beamformed waves from the acoustic waves of each receiver. Then, eight pre-stack migration images are collected with the azimuths of $\mathrm{N} 0^{\circ}, \mathrm{N} 45^{\circ}, \mathrm{N} 90^{\circ}, \mathrm{N} 135^{\circ}, 180^{\circ}, \mathrm{N} 225^{\circ}$, $\mathrm{N} 270^{\circ}$, and $\mathrm{N} 315^{\circ}$. A two-dimensional profile is comprised of the two images with azimuth values $180^{\circ}$ apart, as shown in Fig. 11. The target borehole demarcated by the dashed frame in the $\mathrm{N} 180^{\circ}$ panel is the clearest, and the distance of the target borehole from the logging tool is approximately $11.0 \mathrm{~m}$.

\section{Conclusions}

In this paper, we introduced a method to locate a near-borehole geologic structure with the azimuthal acoustic data and verified the performance of the downhole measurements. We performed field validation in two adjacent fluid-filled boreholes using the supporting logging tool. As the P-wave wavelength in the rock formation and the diameter of the target borehole were of equal magnitude, the acoustic waves from the target borehole were dominated by the scattered P-waves. In the azimuthal acoustic data processing workflow, the beamforming method was used to directionally receive the acoustic waves and ensure that the stack of the scattered P-waves was in-phase.

The results showed that the azimuthal variation in the scattering amplitudes is apparent. The azimuth of the target borehole that corresponded to the maximum amplitude was $\mathrm{N} 150^{\circ}$, which was extremely close to its actual value $\mathrm{N} 147^{\circ}$. Moreover, the target borehole was displayed in the multi-azimuth imaging results, at a distance of approximately $11.0 \mathrm{~m}$ from the borehole. It can be seen that the measured values of the azimuth and distance based on the scattered P-waves are consistent with the actual values, indicating the reliability of the evaluation of near-borehole geologic structures using acoustic scattering. The azimuthal acoustic measurements can also be used to obtain detailed elastic properties of rock formation, making it an essential application for downhole measurements. However, monopole sources generate more mode waves than dipole sources in a fluid-filled borehole, and the attenuation of high-frequency P-waves in 


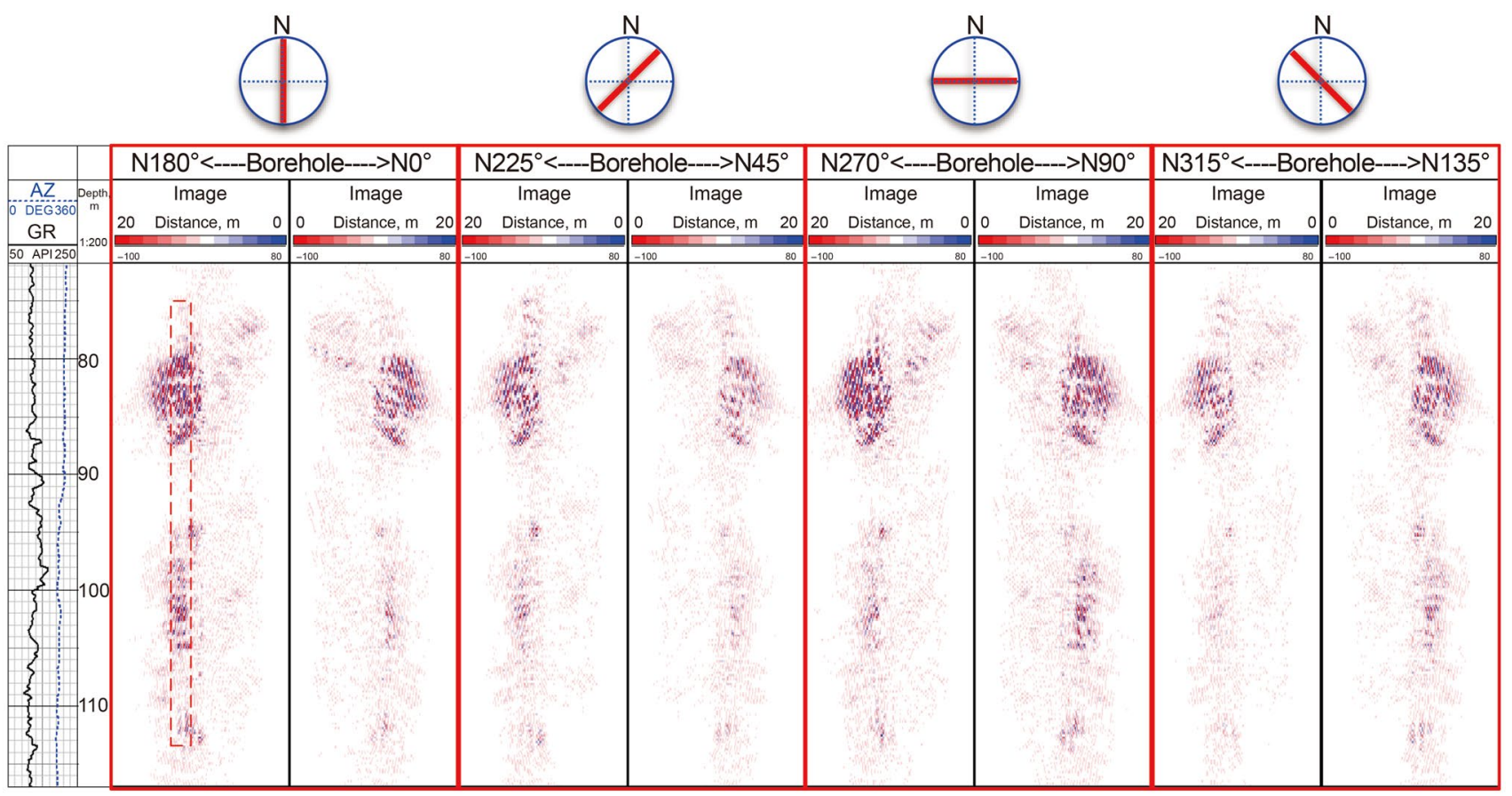

Fig. 11 Multi-azimuth images of the target borehole. The target borehole is located in the south, separated by approximately $11.0 \mathrm{~m}$

rocks cannot be ignored. It should be noted that these factors present an obvious challenge for effectively picking up the scattered P-waves from low SNR acoustic data and further research are essential for field application.

Acknowledgements The authors would like to thank the editors and reviewers for their valuable comments. This work was supported by the National Natural Science Foundation of China (41874210 and 11734017), the National Science and Technology Major Project (2017ZX05019001 and 2017ZX05019006), the Petro China Innovation Foundation (2016D-5007-0303), and the Science Foundation of China University of Petroleum, Beijing (2462016YJRC020). The field testing was carried out in cooperation with the China Petroleum Logging Co., Ltd.

Open Access This article is licensed under a Creative Commons Attribution 4.0 International License, which permits use, sharing, adaptation, distribution and reproduction in any medium or format, as long as you give appropriate credit to the original author(s) and the source, provide a link to the Creative Commons licence, and indicate if changes were made. The images or other third party material in this article are included in the article's Creative Commons licence, unless indicated otherwise in a credit line to the material. If material is not included in the article's Creative Commons licence and your intended use is not permitted by statutory regulation or exceeds the permitted use, you will need to obtain permission directly from the copyright holder. To view a copy of this licence, visit http://creativecommons.org/licenses/by/4.0/.

\section{References}

Aki K. Analysis of the seismic coda of local earthquakes as scattered waves. J Geophys Res. 1969;74(2):615-31. https://doi. org/10.1029/JB074i002p00615.

Aki K, Chouet B. Origin of coda waves: source, attenuation, and scattering effects. J Geophys Res. 1975;80(23):3322-42. https://doi. org/10.1029/JB080i023p03322.

Chabot L, Henley DC, Brown RJ, et al. Single-well imaging using the full waveform of an acoustic sonic. SEG technical program expanded abstracts. 2001;420-3. https://doi.org/10.1190/1.18166 34.

Che XH, Qiao WX, Ju XD, et al. An experimental study on azimuthal reception characteristics of acoustic well-logging transducers based on phased-arc arrays. Geophysics. 2014a;79(3):D197-204. https://doi.org/10.1190/geo2013-0334.1.

Che XH, Qiao WX, Wang RJ, et al. Numerical simulation of an acoustic field generated by a phased arc array in a fluid-filled cased borehole. Pet Sci. 2014b;11(3):385-90. https://doi.org/10.1007/ s12182-014-0352-3.

Che XH, Qiao WX, Ju XD, et al. Experimental study of the azimuthal performance of 3D acoustic transmitter stations. Pet Sci. 2016;13(1):52-63. https://doi.org/10.1007/s12182-015-0073-2.

Che XH, Qiao WX, Ju XD, et al. Experimental study on the performance of an azimuthal acoustic receiver sonde for a downhole tool. Geophys Prospect. 2017;65(1):158-69. https://doi. org/10.1111/1365-2478.12401.

Fang XD, Fehler MC, Zhu ZY, et al. Reservoir fracture characterization from seismic scattered waves. Geophys J Int. 2014;196(1):481-92. https://doi.org/10.1093/gji/ggt381.

Gou LM. A study on scattered wave imaging processing technique. Ph.D. thesis. Beijing: China University of Geosciences (Beijing). 2007 (in Chinese).

Haldorsen J, Voskamp A, Thorsen R, et al. Borehole acoustic reflection survey for high resolution imaging. SEG technical program 
expanded abstracts. 2006;314-8. https://doi.org/10.1190/1.23701 82.

Haldorsen J, Zhu F, Hirabyashi N, et al. Borehole acoustic reflection survey (BARS) using full waveform sonic data. First Break. 2010;28:33-8.

Hornby BE. Imaging of near-borehole structure using full-waveform sonic data. Geophysics. 1989;54(6):747-57. https://doi. org/10.1190/1.1442702.

Li C, Yue WZ. High-resolution adaptive beamforming for borehole acoustic reflection imaging. Geophysics. 2015;80(6):565-74. https://doi.org/10.1190/geo2014-0517.1.

Maercklin N, Haberland C, Ryberg T, et al. Imaging the dead sea transform with scattered seismic waves. Geophys J Int. 2004;158(1):179-86. https://doi.org/10.1111/j.1365246X.2004.02302.x.

Maia W, Rúbio R, Junior F, et al. First borehole acoustic reflection survey mapping a deepwater turbidite sand. SEG 76th annual international meeting expanded abstracts. 2006;1757-61. https:// doi.org/10.1190/1.2369864.

Qiao WX, Ju XD, Che XH, et al. Transducers and acoustic well logging technology. Physics. 2011;40(2):99-106 (in Chinese).

$\mathrm{Su}$ YD, Wei ZT, Tang XM. A validation method of dipole shearwave remote reflection imaging from adjacent borehole reflection. J Appl Acoust. 2014;33(1):29-34. https://doi.org/10.11684 /j.issn.1000-310x.2014.01.005 (in Chinese).

Tang XM. Imaging near-borehole structure using directional acousticwave measurement. Geophysics. 2004;69(6):1378-86. https://doi. org/10.1190/1.1836812.

Tang XM, Patterson DJ. Single-well S-wave imaging using multicomponent dipole acoustic-log data. Geophysics. 2009;74(6):211-23. https://doi.org/10.1190/1.3227150.

Tang XM, Cao JJ, Li Z, et al. Detecting a fluid-filled borehole using elastic waves from a remote borehole. J Acoust Soc Am. 2016a;140:EL211-7. https://doi.org/10.1121/1.4960143.

Tang XM, Li Z, Hei C, et al. Elastic wave scattering to characterize heterogeneities in the borehole environment. Geophys J Int. 2016b;205(1):594-603. https://doi.org/10.1093/gji/ggw037.
Willis ME, Burns DR, Rao R, et al. Spatial orientation and distribution of reservoir fractures from scattered seismic energy. Geophysics. 2006;71(5):43-51. https://doi.org/10.1190/1.2235977.

Wu JP, Qiao WX, Che XH, et al. Experimental study on the radiation characteristics of downhole acoustic phased combined arc array transmitter. Geophysics. 2012;78(1):D1-9. https://doi. org/10.1190/geo2012-0114.1.

Wu RS. Attenuation of short period seismic waves due to scattering. Geophys Res Lett. 1982;9(1):9-12. https://doi.org/10.1029/ GL009i001p00009.

Wu RS, Aki K. Scattering characteristics of elastic waves by an elastic heterogeneity. Geophysics. 1985;50(4):582-95. https://doi. org/10.1190/1.1441934.

Yamamoto H, Watanabe S, Koelman JMV, et al. Borehole acoustic reflection survey experiments in horizontal wells for accurate well positioning. In: SPE/CIM international conference on horizontal well technology, 6-8 November, Calgary; 2000. https://doi. org/10.2118/65538-ms.

Yang SB, Qiao WX, Che XH. Numerical simulation of acoustic field in logging-while-drilling borehole generated by linear phased array acoustic transmitter. Geophys J Int. 2019a;217(2):1080-8. https ://doi.org/10.1093/gji/ggz071.

Yang SB, Qiao WX, Che XH. Numerical simulation of acoustic fields in formation generated by linear phased array acoustic transmitters during logging while drilling. J Pet Sci Eng. 2019b;182:106184. https://doi.org/10.1016/j.petrol.2019.106184.

Yang SB, Qiao WX, Che XH. Numerical simulation of acoustic reflection logging while drilling based on a cylindrical phased array acoustic receiver station. J Pet Sci Eng. 2019c;183:106467. https ://doi.org/10.1016/j.petrol.2019.106467.

Yilmaz Öz. Seismic data analysis: processing, inversion, and interpretation of seismic data. Tulsa: Society of Exploration Geophysicists; 2001. https://doi.org/10.1190/1.9781560801580.

Zhang TX, Tao G, Li JJ, et al. Application of the equivalent offset migration method in acoustic log reflection imaging. Appl Geophys. 2009;6:303-10. https://doi.org/10.1007/s11770-009-0041-y. 